\title{
Glycemic Control X Invisible Risk Factors Among Diabetic Patients In Eastern Province
}

\author{
Mohammed Taha Al-Hariri ${ }^{1}$, Mohammed A M Alhefnawi ${ }^{2}$, Mohamad Jalal Istanbouli ${ }^{2} \&$ Wadee A G Algehlani ${ }^{2}$ \\ ${ }^{1}$ Department of Physiology, College of Medicine, Imam Abdulrahman Bin Faisal University, Dammam, KSA \\ ${ }^{2}$ Department of Architecture, College of Architecture and planning, Imam Abdulrahman Bin Faisal University, \\ Dammam, KSA
}

Correspondence: Mohammed Taha Al-Hariri, Department of Physiology, College of Medicine, Imam Abdulrahman Bin Faisal University. P.O 2114-31451, Dammam, KSA. Tel: 96-650-727-5028. E-mail: mtalhariri@iau.edu.sa

Received: August 31, 2019 Accepted: September 25, 2019 Online Published: September 30, 2019

doi:10.5539/gjhs.v11n12p38 URL: https://doi.org/10.5539/gjhs.v11n12p38

\begin{abstract}
Purpose: The present study tried to compare the glycemic profile of diabetic patients who live in the main two cities of in the Eastern province of (Khobar and Dammam) KSA and to find out the possible links with the environmental factors and socioeconomic status of patients.
\end{abstract}

Methods: This was a retrospective cohort study carried out in King Fahd Teaching Hospital, involving a chart review of diabetic patients during the period 1 January 2018 and 31 December 2018. All of the patients in this study were required to be living in the main studied cities of the eastern province, Saudi Arabia (Dammam and Khobar). The electronic medical records of all participants included: medication, admission, diagnosis, investigations, nursing and surgical. The invisible data (environmental and socioeconomic factors) were collected from the Urban Observatory Eastern Region.

Results: Evolution of the medical records in this study revealed that the level of fasting blood glucose and $\mathrm{HbA} 1 \mathrm{c}$ was significantly higher among the resident of the Al-Khobar city. The dramatic changes in socioeconomic behaviours in the KSA along with the lack of public Education about diabetes mellitus and the imbalance between food intake and energy expenditure has brought as a real health risk for Diabetes mellitus in the Al-Khobar city, KSA. By linking the findings, the environment in Dammam tends to be healthier for its residents compared to Khobar in regard to open spaces, and pollution indicators. Moreover, The results showed that, residents of the Al-Khobar city have a higher income.

Conclusion: The present findings suggest that there are many unseen risk factors may influence the progress and aggravation of diabetes mellitus. Very restrict strategies that create opportunities for diabetic patients to promote their health education are highly needed to control or reduce the expected diabetic complications.

Keywords: diabetes mellitus, glycemic profile, environment, hospital

\section{Introduction}

\subsection{Diabetes Mellitus}

Diabetes mellitus is a heterogeneous disease that is associated with multiple macrovascular and microvascular complications (Association, 2018a). In type-2 diabetes, various environmental, genetic and metabolic stress can result in the progressive loss of beta cell function and/or mass that manifests clinically as hyperglycemia (Association, 2019). Long-term complications of diabetes mellitus include: Atherosclerotic cardiovascular disease defined as peripheral arterial disease with risk of foot ulcers, coronary heart disease and cerebrovascular disease (Association, 2018b); nephropathy leading to renal failure; retinopathy with potential loss of vision; peripheral neuropathy, amputations, and Charcot joints; and autonomic neuropathy causing sexual, genitourinary, gastrointestinal dysfunction and cardiovascular symptoms (Kerner \& Brückel, 2014).

Diabetes mellitus as an increasingly important disease would be one of the common cause of mortality and morbidity in the world (Wild et al., 2004). Diabetes mellitus is one of the fastest-growing health concerns in the Kingdom of Saudi Arabia (KSA). According to the international report, KSA is among the top ten countries 
globally with prevalence of $23.9 \%$ (Aldossari et al., 2018).

In parallel with the global figure of diabetes mellitus pandemic. Diabetes can have an impact on the quality of life, but are also associated with lifestyle and/or environmental factors (Kolb \& Martin, 2017).

\subsection{Diabetes and Invisible Risk Factors}

Based on recent evidence in the literature, diabetes mellitus hypothesized to be an outcome of the interaction of biological, behavioural, demographic and socioeconomic factors. Moreover, they considered as an important predictor for diabetes mellitus (Dendup et al., 2018).

Many studies have demonstrated the adverse effect of many invisible risk factors on health. living, socioeconomic and environmental factors play a very vital role in the etiopathogenesis of diabetes mellitus (Kolb \& Martin, 2017).

Socioeconomic status is defined as the total measure of an individual's and/or families social and economic position $(\mathrm{Hu}, 2011)$.

A lot of researchers and centers in KSA are trying to control and monitor diabetes mellitus for decades to figure out the extent of this disease that impacts on individual and society's productivity and will substantially increase the demand for health care services. In KSA, very little research has tackled the indirect and the so-called socioincome impact on diabetic patients, whereas it is evident that the poor built environment conditions and Urbanism aggravate diabetes and/or its complications (Sidawi \& Al-Hariri, 2012).

\subsection{The Eastern Province}

The eastern region is located in the eastern part of the Kingdom between latitude 29.3 north and latitude 23.3 south, and east of longitude 51 and west of longitude 54, and the region takes the shape of the triangle where the Arabian Gulf forms its eastern side, the second side is the southern border of the Kingdom with the Sultanate of Oman and the Republic of South Yemen, and the third leg borders the area adjacent to Riyadh and the northern region of the Kingdom. The city of Dammam is located between the waters of the Arabian Gulf and the dunes of the desert of Dahana, including the cities of Dammam and Khobar. The city of Dammam does not have a large variety of contours, as the maximum level reaches $10 \mathrm{~ms}$ in some of those areas.

\subsection{The Urban, Social and Economic Structure of the Study Area}

In terms of the physical structure of the city of Dammam, it is clear that Dammam has the highest percentage of urbanization. It is considered the administrative and service center with the highest regional services in the eastern region. The distribution of the population by age is an important demographic variable, since the imbalance of gender ratio of the population affects the future composition of the population and determines future population growth rates and patterns of social and economic relations that prevail in society, and the qualitative composition of the population in society is specific to the types of its activities and the economic and social roles prevailing in this society.

The present study tried to compare the glycemic profile of diabetic patients who live in the main two cities of in the Eastern province of (Khobar \& Dammam) KSA and to find out the possible links with the environmental factors and socioeconomic status of patients.

\section{Methodology}

This was a retrospective cohort study carried out in King Fahd Teaching Hospital (KFHU) of the University, in the Eastern province of KSA, involving a chart review of diabetic patients type- 2 of both sexes who were over 18 years old, diagnosed according to the WHO criteria (Definition 2006), and visited the KFHU between 1 January 2018 and 31 December 2018. All of the patients in this study were required to be living in the main studied cities (Dammam \& Khobar) and to visit the KFHU at least once a year during the 4-year period (Yi et al., 2018). The proposal was approved by the institutional review board of Imam Abdulrahman Bin Faisal University (IRB-201406-202).

\subsection{Data Collection and Outcomes Measured}

The electronic medical records from the KFHU database were processed using the QuadraMed ${ }^{\circledR}$ system. The records included residential area, age, monthly income, marital status, gender, medication, admission, diagnosis, investigations, nursing and surgical.

Socio-demographic, pollution and geographic data of the two cities were collected from Urban Observatory Eastern Region - Urban Indicators: Cities of the Eastern Region, Urban Observatory Dammam City - Urban Indicators and Report of the prosperity of the cities of the capital of the Dammam - the first draft (RPC,2017). 


\subsection{Statistical Analysis}

Data were collected in Microsoft Excel and imported into the Statistical Package of Social Studies (SPSS, windows version 22.0) for statistical analysis. Continuous data were compared using the Mann Whitney u test (Dammam vs. Khobar). All the results were presented as mean $\pm \mathrm{SD}$ and were considered statistically significant when $p<0.05$.

\section{Results}

\subsection{Patients Demographics and Clinical Characteristics}

The baseline characteristics of 3256 diabetic patients were as follows: most of the patients were females (2775) and from Khobar city (Table 1).

Table 1. Sex X address distribution

\begin{tabular}{llccc}
\hline & & Dammam & Khobar & Total \\
\hline \multirow{2}{*}{ Sex } & Male & 155 & 326 & 481 \\
& Female & 844 & 1931 & 2775 \\
\hline Total & & 999 & 2257 & 3256 \\
\hline
\end{tabular}

Table 2 summarizes patient demographics The mean age of the studied patients was $59 \pm 13$. The mean FBS and $\mathrm{HbA} 1 \mathrm{c}$ measurements during time periods was $119 \pm 36$ and $7.4 \pm 3.3$ respectively. About $30.7 \%$ of the patients were found in Dammam City and 69.3\% in Khobar city. The majority of patients were females (80\%).

Table 2. Demographics of patients

\begin{tabular}{ll}
\hline Mean age & $59 \pm 13$ \\
\hline Mean FBG/HbA1c & $119 \pm 36 / 7.4 \pm 3.3$ \\
\hline Living in Dammam/Khobar, \% & $30.7 / 69.3 \%$ \\
\hline Female/Male, \% & $80 / 20$ \\
\hline
\end{tabular}

When the mean level of FBG/HbA1c of patients in the two studied cities have compared, the resident in Al-Khobar city showed a higher statistically significant $(p<0.05)$ level $(122 \pm 4 / 7.8)$ than those who live in Al-Dammam city (114 $\pm 3 / 6$.$) As shown in Figures (1 and 2).$

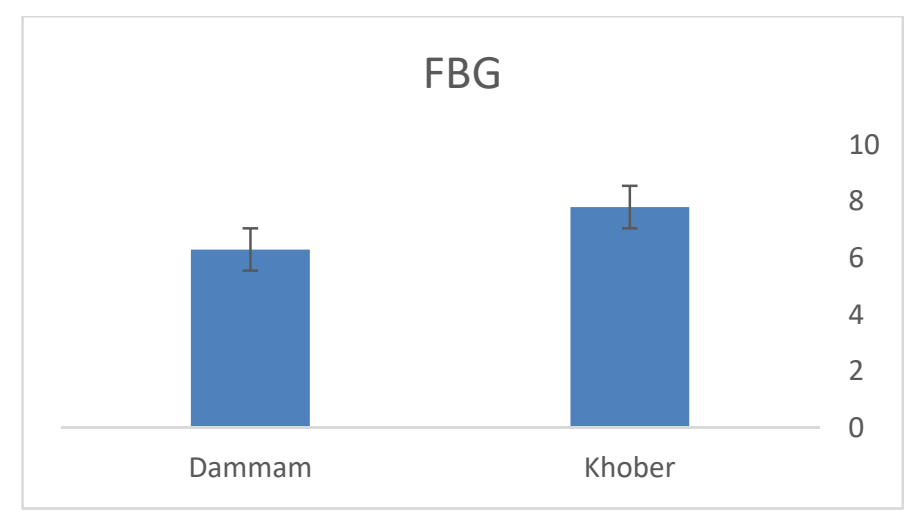

Figure 1. FBG level of patients in the cities studied 


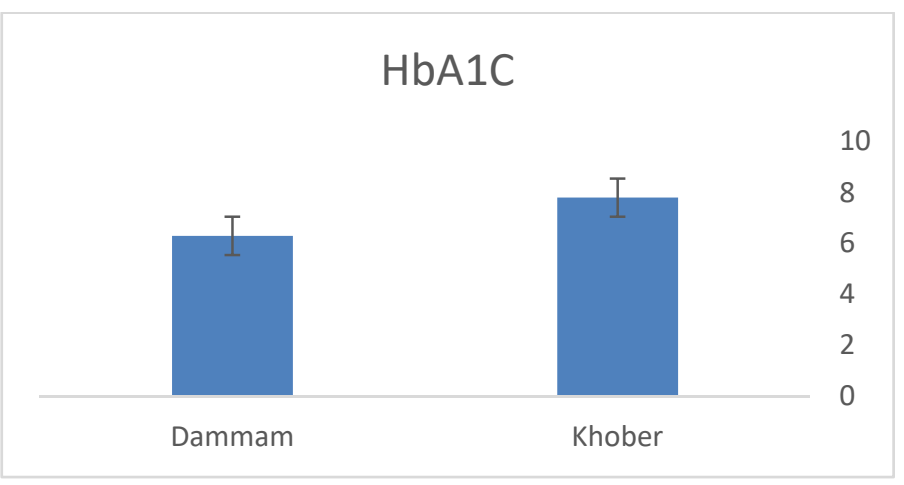

Figure 2. HbA1C level of patients in the cities studied

Table 3. Air pollution rates of carbon monoxide (UODC, 2015)

\begin{tabular}{llll}
\hline Region & Standard limit (ppm) & Dammam (ppm) & Khobar (ppm) \\
\hline Air Pollution Rates of Carbon Monoxide & 9.0 & 0.20 & 0.60 \\
\hline
\end{tabular}

Comparing between Dammam and Khobar regarding Carbon Monoxide pollution. As illustrated in Table 3, pollution in Khobar is almost three times as that in Dammam.

Table 4. Volume of sulfur oxides emissions (UODC,2015)

\begin{tabular}{llll}
\hline Region & Standard limit (ppm) & Dammam (ppm) & Khobar (ppm) \\
\hline Volume of sulfur oxides emissions & 0.030 & 0.007 & 0.013 \\
\hline
\end{tabular}

Comparing between Dammam and Khobar regarding sulfur oxides emissions pollution. As illustrated in Table 4, pollution in Khobar is almost twice as that in Dammam.

Table 5. Volume of Ozone gas emissions (UODC, 2015)

\begin{tabular}{llll}
\hline Region & Standard limit (ppm) & Dammam (ppm) & Khobar (ppm) \\
\hline Volume of Ozone Emissions & 0.08 & 0.021 & 0.032 \\
\hline
\end{tabular}

Comparing between Dammam and Khobar regarding Ozone Emissions pollution. As illustrated in Table 5, pollution in Khobar is one and a half as that in Dammam.

Table 6. Average monthly household's savings (UODC, 2015)

\begin{tabular}{lc}
\hline The City & Saving/Month (Riyal) \\
\hline Dammam & 2081 \\
Al- Kohbar & 6200 \\
\hline
\end{tabular}

As shown in Table 6. The Average value of monthly savings in the families in Khobar is almost three folds as that in Dammam. Consequently, lifestyles, living conditions, types of diet and housing are expected to be widely different in both cities. Therefore, Diabetic pattern might be impacted by this factor as noticed in the samples in both cities. 
Table 7. Urban Population Density (RPC, 2016)

\begin{tabular}{lccc}
\hline City & Land area $\left(\mathrm{Km}^{2}\right)$ & Population no. & Density $\left(\right.$ Person $\left./ \mathrm{km}^{2}\right)$ \\
\hline Dammam & 182233.1 & 1082438 & 5.94 \\
Khobar & 7676.7 & 696231 & 90 \\
\hline
\end{tabular}

As shown in Table 7, the total area of Dammam city is very much bigger compared to the area of Khobar city. As a result, the population density in Dammam city is very much smaller than in Khobar city. This factor reflects the huge crowds and the very limited open spaces in Khobar compared to Dammam.

Table 8. Cultivated lands (RPC, 2016)

\begin{tabular}{lcc}
\hline City & Cultivated lands $\left(\mathrm{Km}^{2}\right)$ & Per capita Cultivated lands $/ \mathrm{m}^{2}$ \\
\hline Dammam & 74.5 & 0.068 \\
Khobar & 25.1 & 0.036 \\
\hline
\end{tabular}

Table 8 Indicates that Dammam has an area of cultivated land that equals to almost three times that in Khobar.

Table 9. The average area of dwelling units (UOER, 2017)

\begin{tabular}{lccccc}
\hline The City & $\begin{array}{c}\text { Average area of the } \\
\text { Building }\left(\mathrm{m}^{2}\right)\end{array}$ & $\begin{array}{c}\text { Average number of } \\
\text { floors/Building }\end{array}$ & $\begin{array}{c}\text { Average number } \\
\text { of units/Building }\end{array}$ & $\begin{array}{c}\text { Average number } \\
\text { of rooms }\end{array}$ & $\begin{array}{c}\text { Average area of } \\
\text { the unit }\left(\mathrm{m}^{2}\right)\end{array}$ \\
\hline Dammam & 507.59 & 3 & 6 & 5 & 253.8 \\
Al- Kohbar & 458.84 & 4 & 8 & 5 & 229.4 \\
\hline
\end{tabular}

As shown in Table 9 the average area of the dwelling unit in Dammam is larger than in Khobar. This might affect the daily lifestyle and activities of residents. As larger dwelling units face the residents to be more active, moving around the unit, that is the case in Dammam, wherein Khobar, the small size dwelling units limit the indoor movements. Which might increase the probability of getting diabetes.

\section{Discussion}

To the best of our knowledge, our study is one of the first to use electronic medical records from KFHU to evaluate the glycemic control of diabetic patients in relation to the environmental and socioeconomic factors among the residents of the main two big cities in the Estero province KSA.

Evolution of the medical records in this study revealed that the level of FBG and HbAlc was significantly higher among the resident of the Al-Khobar city. The dramatic changes in socioeconomic behaviours in the KSA along with the lack of public Education about diabetes mellitus and the imbalance between food intake and energy expenditure has brought as a real health risk for Diabetes mellitus in Al-Khobar city, KSA (Mugharbel \& Al-Mansouri, 2003).

By linking the findings, the environment in Dammam tends to be healthier for its residents compared to Khobar in regard to open spaces, and pollution indicators as noted in Tables 3-5. Environmental pollution has been reported to aggravate the diabetic patients and aggravate the risk of hyperlipidemia and hypertension, Moreover, it could discourage the performance of physical activities (Dendup et al., 2018).

The results of the current work showed that, residents of the Al-Khobar city have a higher income (Table 6) do reveal some bad habits such as watching TV or working long hours at the office. As proved that a sedentary lifestyle is significantly associated with the incidence of type 2 diabetes (Joseph et al., 2016).

Moreover, the density Person/km2 and excessive green land (Tables 7-9) has positive impacts upon the natural environment there, it considered as a good indicator against the levels of pollution and acts as a lung where the residents of Dammam can get pure air, it also promotes walking activities for the residents of Dammam. This indicator might have a strong impact on the variation in diabetic results of the samples in the two cities (Berke et al., 2007).

It proved that the socioeconomic and building environment affected the health status through a number of 
pathways such as; physiological and psychosocial pathways (Guise, Barton, \& Grant 2010).

Based on the nature and the environmental features of the studied cities together and relating them to the present findings, it can be suggested that: many links between the glycemic level and other external factors such as environmental pollution, green land and income.

Diabetes mellitus has considered a significant burden in KSA because of the economic, healthcare system administrative and social costs associated with diabetes and its related complications (Naeem, 2015). Unfortunately, the evidence from the literature suggest that the KSA's external environment is unhealthy due to the irregular setting of amenities, such as: recreation facilities, gardens, sport centers parks temperature and many other indoor and outdoor factors which force diabetic patients to adopt social and domestic lives that contribute to the deterioration in the glycemic control and aggravate and/or accelerate the bad outcomes of the disease such as early pain, mortality, disability, suffering, absenteeism and loss of productivity from disease-related complications (Sidawi, Deakin, \& Al-Hariri 2016).

A previous study conducted in KSA found that obesity was more prevalent among, high-income patients who were residing in urban cities (Al-Nuaim et al., 1996). Obesity is an important risk factor for impaired glucose tolerance metabolic syndrome, type two diabetes mellitus and its related complications (Katušić et al., 2005).

It was known the influences of interactions between the socioeconomic state of the patient in the pathogenesis of type-2 diabetes. Many evidences linked the association of inherited genetic susceptibility as an important risk factor for common type-2 diabetes and the environmental factors that may change in genes expression, making the genes potentially important pathogenic mechanisms in Diabetes militias and its related complications (Murea, Ma, \& Freedman, 2012).

The general environmental risk factors could affect many illnesses dependent on the genetic susceptibility of patients. The genetic effect is defined as gene-environment interactions that are parallel to the spectrum of environmental exposure, which confirm the significant contribution of the external factors on the etiopathogensis of the disease (Franks, 2011).

Therefore, residential development planners must include environments that promote a safe space to allow physical activity for the citizens along with an aggressive promotion of public health awareness through different health education programs and continued community-based screening campaigns

The strength of this study is a good and representative sample in the main studied cities. Therefore, the results could provide the baseline evidence for more related environment interactions in relation to diabetes mellitus.

\subsection{Limitation}

This study had some limitations. Although, the finding of this study showed influences of invisible factors on glycemic control, however, some variables such as body mass index, history of family illness were not included in the study. It should be recommended to collect the socioeconomic factors data in the upcoming validated survey.

\section{Conclusion}

The present findings suggest that there are many unseen risk factors may influence the progress and aggravation of diabetes mellitus and also provides a reasonable basis for further longitudinal studies and better quality investigation along with environmental policy and measurements to provide an insight to support "health-orientated" city planning and urban design.

\section{Competing Interests Statement}

The authors declare that there are no competing or potential conflicts of interest.

\section{References}

Al-Nuaim, A., Al-Rabeaan, K., Al-Mazrou, Y., Al-Attas, O., Al-Daghari, N., \& Khoja, J. (1996). High prevalence of overweight and obesity in Saudi Arabia. International journal of obesity, 20, 547-552.

Aldossari, K. K., Aldiab, A., Al-Zahrani, J. M., Al-Ghamdi, S. H., Abdelrazik, M., Batais, M. A., ... \& El-Metwally, A. (2018). Prevalence of prediabetes, diabetes, and its associated risk factors among males in Saudi Arabia: a population-based survey. Journal of diabetes research. https://doi.org/10.1155/2018/2194604

Association, A. D. (2018a). 2. Classification and diagnosis of diabetes: standards of medical care in diabetes-2018. Diabetes care, 41, S13-S27. https://doi.org/10.2337/dc18-S002

Association, A. D. (2018b). 9. Cardiovascular disease and risk management: standards of medical care in diabetes-2018. Diabetes care, 41, S86-S104. https://doi.org/10.2337/dc18-S009

Association, A. D. (2019). Classification and diagnosis of diabetes: standards of medical care in diabetes-2019. 
Diabetes Care, 42, S13-S28. https://doi.org/10.2337/dc19-S002

Berke, E. M., Koepsell, T. D., Moudon, A. V., Hoskins, R. E., \& Larson, E. B. (2007). Association of the built environment with physical activity and obesity in older persons. American journal of public health, 97(3), 486-492. https://doi.org/10.2105/AJPH.2006.085837

Definition, W. (2006). Diagnosis of diabetes mellitus and intermediate hyperglycemia: report of a WHO/IDF consultation. Geneva: World Health Organization, 3. https://apps.who.int/iris/handle/10665/43588

Dendup, T., Feng, X., Clingan, S., \& Astell-Burt, T. (2018). Environmental risk factors for developing type 2 diabetes mellitus: a systematic review. International journal of environmental research and public health, 15(1), 78. https://doi.org/10.3390/ijerph15010078

Franks, P. W. (2011). Gene× environment interactions in type 2 diabetes. Current diabetes reports, 11, 552. https://doi.org/10.1007/s11892-011-0224-9

Guise, R., Barton, H., \& Grant, M. (2010). Shaping Neighbourhoods: For Local Health and Global Sustainability. Routledge.

Hu, F. B. (2011). Globalization of diabetes: the role of diet, lifestyle, and genes. Diabetes care, 34, 1249-1257. https://doi.org/10.2337/dc11-0442

Joseph, J. J., Echouffo-Tcheugui, J. B., Golden, S. H., Chen, H., Jenny, N. S., Carnethon, M. R., ... \& Ouyang, P. (2016). Physical activity, sedentary behaviors and the incidence of type 2 diabetes mellitus: the Multi-Ethnic Study of Atherosclerosis (MESA). BMJ Open Diabetes Research and Care, 4, e000185. http://dx.doi.org/10.1136/bmjdrc-2015-000185

Katušić, D., Tomić, M., Jukić, T., Kordić, R., Šikić, J., Vukojević, N., \& Šarić, B. (2005). Obesity-a risk factor for diabetic retinopathy in type 2 diabetes? Collegium antropologicum, 29(1), 47-50.

Kerner, W., \& Brückel, J. (2014). Definition, classification and diagnosis of diabetes mellitus. Experimental and Clinical Endocrinology \& Diabetes, 122(7), 384-386. http://doi.org/10.1055/s-0034-1366278

Kolb, H., \& Mart, S. (2017). Environmental/lifestyle factors in the pathogenesis and prevention of type 2 diabetes. BMC medicine, 15, 131. http://doi.org/10.1186/s12916-017-0901-x

Mugharbel, K. M., \& Al-Mansouri, M. A. (2003). Prevalence of obesity among type 2 diabetic patients in Al-khobar primary health care centers. Journal of family \& community medicine, 10(2), 49.

Murea, M., Ma, L., \& Freedman, B. I. (2012). Genetic and environmental factors associated with type 2 diabetes and diabetic vascular complications. The review of diabetic studies: RDS, 9(1), 6-22 http://doi.org/10.1900/RDS.2012.9.6

Naeem, Z. (2015). Burden of diabetes mellitus in Saudi Arabia. International journal of health sciences, 9(3), V-VI. https://doi.org/10.12816/0024690

Sidawi, B., \& Al-Hariri, M. T. A. (2012). The impact of built environment on diabetic patients: the case of Eastern Province, Kingdom of Saudi Arabia. Global journal of health science, 4(4), 126-138. http://doi.org/10.5539/gjhs.v4n4p126

Sidawi, B., Deakin, M., \& Al-Hariri, M. T. A. (2016). The place-based impact of built environments: Diabetes, living conditions, homes and neighbourhoods. Indoor and Built Environment, 25(3), 495-508. https://doi.org/10.1177/1420326X14556909

UOER. (2017). Urban Observatory Eastern Region - Urban Indicators: Cities of the Eastern Region 1438H-2017M - Municipality of the Eastern Region - Ministry of Municipal and Rural Affairs.

Wild, S., Roglic, G., Green, A., Sicree, R., \& King, H. (2004). Global prevalence of diabetes: estimates for the year 2000 and projections for 2030. Diabetes care, 27, 1047-1053. https://doi.org/10.2337/diacare.27.5.1047

Yi, Y., Li, Y., Hou, A., Ge, Y., Xu, Y., Xiong, G., .. \& Xu, H. (2018). A Retrospective Cohort Study of Patients with Type 2 Diabetes in China: Associations of Hypoglycemia with Health Care Resource Utilization and Associated Costs. Diabetes Therapy, 9(3), 1073-1082. https://doi.org/10.6084/m9.figshare.5972734.

\section{Copyrights}

Copyright for this article is retained by the author(s), with first publication rights granted to the journal.

This is an open-access article distributed under the terms and conditions of the Creative Commons Attribution license (http://creativecommons.org/licenses/by/4.0/). 